\title{
LA PONDERACIÓN COMO MÉTODO PARA RESOLVER CONFLICTOS DE PRINCIPIOS Y DERECHOS LABORALES Y DE SEGURIDAD SOCIAL. EL CASO COLOMBIANO
}

\author{
Juan Manuel Charria Segura* \\ Pontificia Universidad Javeriana, Colombia
}

\begin{abstract}
RESUMEN: El trabajo comienza con una breve descripción conceptual de la ponderación, su genealogía, sus alcances axiológicos y los límites argumentativos inherentes a esta metodología de resolución de conflictos de derechos fundamentales. Continúa con el reconocimiento que la ponderación ha tenido en los ordenamientos jurídicos y la jurisprudencia en el ámbito latinoamericano, con especial énfasis en las sentencias del Tribunal Constitucional Colombiano y las críticas que se han formulado a esta herramienta jurídica. Finaliza, señalando como el método de la ponderación se ha aplicado en el Derecho Laboral y de la Seguridad Social en Colombia.
\end{abstract}

Palabras clave: ponderación, derecho constitucional del trabajo, seguridad social, eficacia de los derechos fundamentales.

ABSTRACT: The paper begins with a brief conceptual description of the weighting, its genealogy and axiological and argumentative limits inherent to this metohodology of conflict resolution of fundamental rights. It continues with the recognition that the weighting has in the legal orders and the jurisprudence in the Latin American context, with special emphasis on the Colombian Constitutional Court's judgments and criticisms that have been leveled at this legal tool. It ends indicating how the method of weighting has been applied in the Labor and Social Security in Colombia.

Key words: weighting, labor constitutional law, social security, fundamental rights efficacy.

\section{EL CONCEPTO DE PONDERACIÓN Y SU RELEVANCIA PRÁCTICA EN AMÉRICA LATINA}

\subsection{BREVE DESARROLLO CONCEPTUAL DE LA PONDERACIÓN}

La ponderación ha sido caracterizada por ser un método encaminado a la aplicación de los principios -entendidos como normas- cuya estructura contiene mandatos de optimización. En este orden de ideas, es preciso explicar que cuando el juez se encuentra frente a un caso en el cual las posibilidades jurídicas se encuentran limitadas, por la aplicación de normas que ordenan "que algo sea realizado en la mayor medida posible, dentro de las posibilidades jurídicas y reales

\footnotetext{
* Abogado de la Pontificia Universidad Javeriana. Especializado en Derecho Laboral y Seguridad Social por el Colegio Mayor de Nuestra Señora del Rosario y en Derecho Sustantivo y Contencioso Constitucional por la Pontificia Universidad Javeriana. Gobernador del Colegio de Abogados Especializados en Derecho del Trabajo y de la Seguridad Social de Colombia. Profesor universitario en las universidades: Javeriana, Jorge Tadeo Lozano, El Bosque, De la Sabana y Los Libertadores. Columnista de la revista Actualidad Laboral y de la Seguridad Social de Legis Editores. Autor de los libros Reflexiones Constitucionales I y II (2006 y 2011). Gerente General de la firma Charria Segura Abogados Asociados. Consultor privado. Contacto: jmcharriasegura@hotmail.

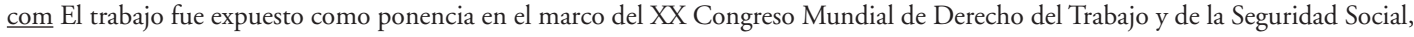
Santiago, Chile, 2012.
} 
existentes"1, debe este realizar un juicio de ponderación que "si bien no puede reducir la subjetividad del intérprete, en ella sí puede fijarse, cuál es el espacio en donde yace esta subjetividad, cuál es el margen para las valoraciones del juez y cómo dichas valoraciones constituyen también un elemento para fundamentar las decisiones" ${ }^{2}$. Si bien este concepto se rige por cierta estructura y reglas lógicas, que permiten una aplicación a lo menos racional, la subjetividad del juez siempre está presente en su recorrido argumentativo, de tal modo que tanto el grado de afectación de los principios, como su peso abstracto y la proporcionalidad en sentido estricto, a través de la argumentación del caso concreto, hacen parte de lo que es en sí la propia subjetividad del juzgador.

Lo anterior comprende un ejercicio mental por parte del juez para instituir entre los dos principios en conflicto lo que la doctrina ha denominado una "jerarquía axiológica móvil", en la que de una parte, exista una jerarquía axiológica como una relación de valor realizada por el intérprete, a través de un juicio de valor subjetivo, prevaleciendo el principio de mayor valor axiológico (lo cual no significa que se invalide o abrogue el otro principio, sino que se deja de lado para el caso particular), y de otra, la jerarquía móvil que representa el valor mutable que es pertinente para el caso concreto, pero que podría invertirse en relación con un caso diverso. En efecto, cuando aparecen conflictos de principios, en numerosas ocasiones se deben a conflictos de reglas que están impregnadas de principios y, por tanto, al ser excluyentes, el juez sacrifica una en beneficio de la otra, teniendo siempre en cuenta que a veces las reglas también son excluyentes, en la medida en que desarrollan principios que se contradicen en un caso concreto.

"En conclusión, el conflicto de principios y su correspondiente ponderación se presenta en dos casos: a) cuando el legislador, al momento de desarrollar legalmente un principio se ve en la necesidad de sacrificar en mayor o menor medida ese u otro principio...y b) cuando el juez al fallar un caso concreto, se encuentra frente a todas las normas constitucionales que sin embargo no se pueden aplicar al mismo tiempo porque contienen principios contradictorios, debiendo el juez sacrificar una de las dos en favor de la otra"3.

Esto, en observancia de unos sub-principios que conlleva la ponderación misma: la idoneidad, necesidad y proporcionalidad en sentido estricto. La "idoneidad", toda vez que un principio no debe sacrificarse si dicho sacrificio no es idóneo para el fin que persigue y la "necesidad" o "certeza" de que no existen otros mecanismos menos costosos para el principio o derecho que se decide restringir o afectar y finalmente, la proporcionalidad en sentido estricto o ponderación.

Frente a esta situación, la doctrina ha considerado que:

"Los principios exigen la máxima realización posible, relativa tanto a las posibilidades fácticas como a las posibilidades jurídicas. Los subprincipios de idoneidad y de necesidad expresan el mandato de optimización relativo a las posibilidades fácticas. En ellos la ponderación no juega ningún papel. Se trata de impedir ciertas intervenciones en los derechos fundamentales, que sean evitables sin costo para otros principios, es decir, se trata del óptimo de Pareto ${ }^{4}$. Ahora bien,

Cfr. AleXY, Robert. Teoría de los derechos fundamentales. Traducción de Ernesto Garzón Valdés. Madrid, España: Centro de Estudios Políticos y Constitucionales, 1997, pp. 86 y 87.

2 Bernal Pulido, Carlos. "Estructura y límites de la ponderación”, en: Revista DOXA, no 26, 2003, Alicante, España, pp. 225238.

Cfr. Tamayo Jaramillo, Javier. La decisión judicial. Bogotá, Colombia: Biblioteca Jurídica Dike, 2011. pp. 1060 y ss.

Vilfredo PARETo, importante economista, sociólogo y filósofo (1848-1923). 
el principio de proporcionalidad en sentido estricto, se refiere a la optimización relativa a las posibilidades jurídicas"5.

Ahora bien, es necesario para concretar la relación de precedencia entre los principios en colisión, los tres elementos que conforman su estructura: (i) la ley de ponderación, (ii) la fórmula del peso y (iii) la carga de la argumentación. La primera, la "ley de la ponderación", ha sido formulada de la siguiente manera: "La ponderación no es más que la optimización relativa a principios contrapuestos (...) Cuanto mayor sea el grado de insatisfacción o de detrimento de un derecho o de un principio, mayor debe ser la importancia de satisfacer el otro"6. La aplicación de dicha ley exige un despliegue de razonamientos por parte del juzgador en los cuales en primer lugar se debe definir el grado de la no satisfacción o de afectación de uno de los dos principios, la importancia de la satisfacción del principio que juega en sentido contrario y la definición final en la que se determina si la importancia de la satisfacción del principio contrario justifica o no la afectación del otro.

Se tiene entonces que, tanto la "no satisfacción" y la "afectación o intervención", conforman un doble concepto objeto de valoración a través del segundo elemento estructural constituido por la fórmula del peso: esta fórmula establece que el peso concreto de un principio en relación a otro, frente a determinado caso específico, proviene del cociente entre los productos del peso abstracto de cada principio y "la seguridad de las apreciaciones empíricas concernientes a su importancia", lo cual determina si la satisfacción del principio contrario justifica la afectación o la no satisfacción del otro. Lo anterior, a través de la atribución metafórica de un valor numérico a dichas variables por medio de la llamada escala triádica ${ }^{7}$, que dividirá el peso concreto en leve, medio o intenso, y las apreciaciones empíricas en seguro, plausible y evidentemente falso.

Para cerrar la estructura de la ponderación, se cuenta con la carga de la argumentación, que se presenta en el caso en el que la aplicación de la fórmula del peso da como resultado que el peso concreto de los principios en colisión es idéntico, caso en cual debe descartarse cualquier principio opuesto a la libertad jurídica y a la igualdad jurídica.

Sin embargo, en un segundo momento, Robert Alexy, en el epílogo a su Teoría de los derechos fundamentales, consideró que cuando se presenta esta situación, la decisión tomada se entiende como no desproporcionada por encontrarse en el margen de acción que la Constitución misma prevé para el legislador. Es de vital importancia destacar que la operación argumentativa efectuada, a través de la estructura de la ponderación, comprende una doble discrecionalidad, en tanto que instituye un valor jerárquico a los principios en conflicto y cambia su valor relativo de acuerdo al caso concreto. Al interior de la misma, se encuentran tres problemas a resolver en cuanto a la estructura, la racionalidad y la legitimidad. De su legitimidad, depende su racionalidad y cuanto más racional, se torna más legítima; todo lo anterior, seguido de una estructura fundamental para su racionalidad.

Siendo innegables los márgenes de discrecionalidad y subjetividad que comporta el juicio de ponderación, puede concluirse que el establecimiento de la jerarquía axiológica móvil descansa -de manera insalvable- en un juicio de valor:

\footnotetext{
Alexy, Robert; Bernal Pulido, Carlos; Prieto Sanchis, Luis et al. El principio de proporcionalidady la interpretación constitucional. Quito, Ecuador: Gobierno de Ecuador. Ministerio de Justicia. Serie Justicia y Derechos Humanos, 2008.

Alexy, Robert, op. cit. (n. 1), pp. 149 y ss.

No se exige -de manera general- que dicha escala se presente de manera triádica. Pueden crearse más o menos grados de intervención y apreciaciones empíricas de su importancia.
} 
"Es una operación que se pretende controlable y ajustada a ciertos cánones, pero es una operación que, quizás en su parte esencial, se efectúa sin "red normativa", a partir de valoraciones en las que no tiene por qué producirse un acuerdo intersubjetivo. La Constitución, como es obvio, no establece ningún orden jerárquico de valores, bienes o derechos y decide que el sacrificio circunstancial de uno de ellos "merece la pena" desde la perspectiva de la satisfacción pues "decidir que el sacrificio circunstancial de un principio merece la pena desde la perspectiva de la satisfacción de otro entraña, sin duda, una valoración; valoración en la que -aunque no se quiera- pesará la importancia que cada individuo concede a los respectivos bienes en conflicto, así como su propia "cuantificación" de costes y beneficios en el caso concreto".

\subsection{PRESENCIA DE LA METODOlOGía DE LA PONDERACIÓN EN LA JURISPRUdENCIA LATINO} AMERICANA

América Latina, atravesada por un amplio proceso de democratización que llevó a cambios trascendentales de índole constitucional en el último siglo, sigue la tendencia a contener amplios catálogos de derechos fundamentales, principios y valores en sus constituciones. Pese a que la región se encuentra fuertemente influenciada por el constitucionalismo europeo, el proceso de implantación de las ideas liberales y sus rasgos característicos han llevado a numerosos autores a referirse a un "nuevo constitucionalismo latinoamericano"9 en razón a las particularidades de su establecimiento.

Esto ha sucedido con las tesis alemanas de la ponderación, las que -en la actualidad- no se consideran para nada lejanas a los sistemas constitucionales latinoamericanos. "De hecho, el principio de proporcionalidad constituye hoy en día quizá el más conocido y el más recurrente "límite de los límites" a los derechos fundamentales y en esa medida supone una barrera frente a intromisiones indebidas en el ámbito de los propios derechos"10 . Como consecuencia de la implantación de este modelo constitucional en la región, los jueces constitucionales y los demás operadores jurídicos han tenido que cambiar su perspectiva funcional, encaminándola hacia parámetros interpretativos nuevos que los llevan a operaciones de razonamiento más complejo, en las que las técnicas interpretativas propias de los principios constitucionales, hacen cada vez más frecuente el uso jurisprudencial de conceptos de aplicación constitucional como la ponderación, la proporcionalidad, la razonabilidad, la maximización de los efectos normativos de los derechos fundamentales, el efecto de irradiación, y la proyección horizontal de los derechos fundamentales (drittwirkung).

Por ejemplo, en materia laboral la jurisprudencia peruana, a través del Tribunal Constitucional, ha asumido desde su sentencia $045-2004-\mathrm{AI}^{11}$ que el principio de proporcionalidad en sentido estricto se reduce a la denominada "ley de la ponderación" alexiana. Dicha providencia estudia el tema de la igualdad de oportunidades en el acceso al empleo público. En tal sentido, se conceptuó a través del fallo en mención que en sede de igualdad de oportunidades, para "el

\footnotetext{
Cfr. Alexy, Robert; Bernal Pulido, Carlos; Prieto Sanchis, Luis et al, op. cit. (n. 5), p. 113.

Cfr. Rolla, Giancarlo. "La concepción de los derechos fundamentales en el constitucionalismo latinoamericano". Centro di Ricerca sui Sistemi Costituzionali Comparati. Universidad de Génova. Ponencia desarrollada en el VIII Congreso Nacional de Derecho Constitucional. Arequipa, 2005.

10 Cfr. Alexy, Robert; Bernal Pulido, Carlos; Prieto Sanchis, Luis et al, op. cit. (n. 5), p. 10.

11 Se trata de un estudio de constitucionalidad en el que se discute si el otorgamiento de un $10 \%$ adicional como bonificación en la calificación para los magistrados titulares del Poder Judicial y del Ministerio Público que postulen al cargo inmediatamente superior, así como aquellos postulantes, que hayan cursado el programa de formación académica.
} 
examen del trato diferenciado resulta indispensable también el principio de proporcionalidad en sentido estricto o ponderación, en el supuesto que dicho trato ha superado el examen a la luz de los principios de idoneidad y de necesidad". Lo anterior evidencia su forma de aplicación, que para el Tribunal Constitucional peruano comporta la siguiente secuencia lógica:

"Primero, se ha de examinar la idoneidad de la intervención; si la intervención en la igualdad -el trato diferenciado- no es idónea, entonces, será inconstitucional. Por tanto, como se afirmó, no corresponderá examinarlo bajo el subprincipio de necesidad. Por el contrario, si el trato diferenciado -la intervención- fuera idóneo, se procederá a su examen bajo el subprincipio de necesidad. Si aun en este caso, el trato diferenciado superara el examen bajo este principio, corresponderá someterlo a examen bajo el principio de proporcionalidad en sentido estricto o ponderación"12.

Por su parte, en la jurisprudencia chilena se ha proliferado el uso de este juicio de manera primordial -en materia laboral- desde el año 2006, año en el que fue instituido el procedimiento de tutela laboral con el fin de proteger los derechos fundamentales del trabajador. Un ejemplo de su aplicación lo constituye el caso del acceso indebido al correo electrónico del trabajador por parte del empleador. Cabe resaltar que frente al tema, ya se habían resuelto casos por parte de la Dirección de Trabajo chilena. Sin embargo, en la sentencia del juzgado del trabajo de Copiapó de 15 de septiembre de 2008, R.U.C. 08-4-0001305-6/ R.I.T. T-1-2008, confirmada por C.S. Rol 522009, se hace una completa aplicación del principio de proporcionalidad, evidenciando de manera consistente, dentro de la jurisprudencia chilena, una aplicación de las reglas, o alguna de las reglas de la proporcionalidad: (i) adecuación, (ii) idoneidad y (iii) ponderación ${ }^{13}$. Se considera en esta oportunidad que:

"En la mayoría de los ordenamientos jurídicos, incluido el nuestro, se ha impuesto el método de la ponderación guiado por el principio de proporcionalidad en sentido amplio, creado por la jurisprudencia alemana, principalmente a partir de los escritos de Robert Alexy, el cual consiste básicamente en pesar los derechos y bienes en juego, persiguiendo que cada derecho se sacrifique por el otro en la menor medida posible y sólo en la medida que ese sacrificio sea racional y no afecte el ya mencionado núcleo esencial de los derechos fundamentales. Esta ponderación a través del principio de proporcionalidad en sentido amplio, opera a través de tres sub juicios: el de la adecuación, el de la necesidad y el de la proporcionalidad en sentido estricto"14.

Ahora bien, la Corte Constitucional colombiana, desde muy temprano en su existencia ${ }^{15}$, ha entendido el método de la ponderación como un principio constitucional así: "El núcleo esencial de un derecho fundamental es resguardado indirectamente por el principio constitucional de

\footnotetext{
12 En el mismo sentido se pueden consultar las providencias 02370-2007-PA/TC y 01059-2009-PA/TC, frente a la ponderación en asuntos laborales.

13 Por ejemplo, ver las sentencias de las causas rol $\mathrm{N}^{\circ} 1710$, de 6 de agosto de 2010 , considerando $100^{\circ}$, rol $\mathrm{N}^{\circ} 1452$, de 5 de agosto de 2010 , considerando $28^{\circ}$, y rol No 1243 , de 30 de diciembre de 2008 , considerando $23^{\circ}$, entre otras.

14 Sentencia de Juzgado de Letras del Trabajo de Copiapó. R.U.C. 08-4-0001305-6/ R.I.T. T-1-2008, confirmada por C.S. Rol 52-2009.

15 La Corte Constitucional se crea con la expedición de la Constitución Política de Colombia de 1991.
} 
ponderación del fin legítimo a alcanzar frente a la limitación del derecho fundamental, mediante la prohibición de limitaciones desproporcionadas a su libre ejercicio" ${ }^{16}$.

Siguiendo con este breve recuento, la Corte Constitucional ecuatoriana creada con la reforma constitucional de 2008, desde muy temprano buscó introducir la ponderación en sus decisiones. La sentencia N.- 002-09-SAN-CC de 8 de marzo de 2009, Juez Constitucional Sustanciadora: Ruth Seni Pnioargote, luego de un amplio recuento doctrinario acerca de la ponderación busca aplicarla a través de la estructura planteada por Alexy, estableciendo el alto tribunal ecuatoriano que para la solución del caso "compete al Pleno de la Corte Constitucional para el Período de Transición, a partir de la ponderación de derechos, sopesar los principios que han entrado en colisión en el caso concreto para determinar cuál de ellos tiene un peso mayor en las circunstancias específicas y, por tanto, cuál de ellos determina la solución para el caso concreto". Dicha providencia trata el tema de la restricción a la importación libre de impuestos de vehículos automáticos de hasta tres años de fabricación a favor de la población discapacitada.

Ahora bien, la jurisprudencia mexicana, a través del Pleno de la Suprema Corte de Justicia de la Nación (SCJN) y su jurisprudencia 130/2007, establece con pleno carácter vinculante para todos los jueces y tribunales de la federación la obligación de la observancia de dicho principio, fundamentado en el artículo 16 de la Constitución:

"No expresamente y con timidez, la SCJN desde entonces aplicó el principio de proporcionalidad, o lo sugería para el analizar la validez de restricciones a los derechos fundamentales, pero sin la claridad que se hubiera querido. Son ejemplos notables los casos relativos al acceso a la justicia, la proporcionalidad de las penas y las restricciones a la libertad de trabajo".

Tal es el caso de la tesis "Libertad de trabajo. No es absoluta de acuerdo con los principios fundamentales que la rigen (artículo 5o., Párrafo primero, de la Constitución Política de los Estados Unidos Mexicanos)", (Tesis 162, Apéndice al Semanario Judicial de la Federación 1917- 2000, t. I, p. 143) $)^{17}$.

En cuanto a la aplicación de la ponderación en los tribunales brasileños se reconoce que "la Constitución federal no lo reconoce expresamente, pero en la doctrina se entiende que "o bien es una norma constitucional no escrita inherente al aparato jurídico del Estado democrático de derecho" o bien deriva de otros principios, como el del debido proceso legal o el de igualdad"18.

La jurisprudencia es múltiple y variada, y los anteriores son algunos ejemplos de la presencia de esta técnica de solución de conflictos entre principios constitucionales. Abundantes han sido las disciplinas del derecho en las que la ponderación ha sido una herramienta de resolución de conflictos entre principios constitucionales por parte de los tribunales constitucionales latinoamericanos y numerosas han sido sus aplicaciones jurisprudenciales. Los ámbitos del derecho laboral y la seguridad social han encontrado un importante esquema decisional logrado a través de estas técnicas. Examinemos entonces el caso colombiano, tema central de la presente exposición.

\footnotetext{
16 Corte Constitucional. Sentencia T-426 de 1992. M.P. Eduardo Cifuentes Muñoz. Reiterado en las sentencias T-047 de 1995. M.P. Vladimiro Naranjo Mesa, T-576 de 1998. M.P. Alejandro Martínez Caballero, C-116 de 1999. M.P. Martha Victoria Sáchica Méndez, C-942 de 2009. M.P. Jorge Ignacio Pretelt Chaljub.

17 Gil SÁnchez, Rubén. "Recepción jurisprudencial del principio de proporcionalidad en México. Cuestiones Constitucionales", en: Revista mexicana de derecho constitucional, nº 21, 2009, D.F., México.

18 Arnold, Rainer; Martínez Estay, José Ignacio; ZúNiga Urbina, Francisco. "El principio de proporcionalidad en la jurisprudencia del tribunal constitucional”, en: Revista Estudios Constitucionales, año 10, no 1, 2012, Santiago, Chile, pp. 65-116.
} 


\title{
2. LA PONDERACIÓN COMO TÉCNICA JUDICIAL EN COLOMBIA. ANÁLISIS JURISPRUDENCIAL DE LA CORTE CONSTITUCIONAL COLOMBIANA
}

\subsection{LA PONDERACIÓN ENTENDIDA COMO PRINCIPIO CONSTITUCIONAL Y SU ALCANCE MATERIAL}

Este método no ha sido ajeno a la aplicación jurisprudencial colombiana. Existen numerosas evidencias de su aplicación como herramienta de resolución de conflictos entre principios y derechos fundamentales y su aplicación efectiva. La misma Corte Constitucional, desde muy temprano en su existencia, ha entendido el método de la ponderación tal y como se explicó previamente como un principio constitucional así: "El núcleo esencial de un derecho fundamental es resguardado indirectamente por el principio constitucional de ponderación del fin legítimo a alcanzar frente a la limitación del derecho fundamental, mediante la prohibición de limitaciones desproporcionadas a su libre ejercicio"19. Esto ha llevado a que la ponderación se haya convertido en un criterio metodológico indispensable en la actividad judicial, teniendo lugar especialmente en los tribunales constitucionales a través de las sentencias de tutela y de constitucionalidad, en virtud de su labor de aplicación directa de las normas constitucionales que tienen la estructura de principios.

De la mano de la ponderación, surgen en la jurisprudencia colombiana ciertas interrogantes que determinan y restringen la aplicación de los derechos constitucionales. El operador judicial debe preguntarse: ¿cuál derecho constitucional ha de protegerse?, ¿cómo reprochar a una autoridad por violar la Constitución cuando, precisamente, lo que motiva su acción es garantizar el goce efectivo de la misma, aunque en otro de sus ámbitos de protección? Son estos interrogantes los que evidencian que los derechos constitucionales no son absolutos en la medida en que no pueden ser aplicados de forma inconsulta, como si no tuvieran límites, pues la protección y el goce efectivos de un derecho constitucional, puede entrar en conflicto con el ejercicio o con la protección de algún otro derecho o garantía constitucional.

En la sentencia T-556 de 1998, M.P. José Gregorio Hernández Galindo, se consideró que el análisis que debe ser realizado por parte del juez de tutela:

\begin{abstract}
"No es de naturaleza legal, ni termina en la verificación de las reglas que en cierta materia haya consagrado el legislador. El poder de éste es constituido, sometido al Estatuto Fundamental del Estado, subalterno, sujeto al examen constitucional; la tarea del fallador, por eso mismo, es lograr la plena efectividad de la Constitución frente a la misma ley y en relación con las acciones u omisiones de las autoridades públicas (no sólo las legislativas sino también las ejecutivas y jurisdiccionales) y, eventualmente, respecto de aquellas provenientes de los particulares que se aparten de la preceptiva suprema o que la desobedezcan o quebranten".
\end{abstract}

$\mathrm{Al}$ respecto, nuestra Corte Constitucional ha considerado de otra parte, que:

"En ejercicio del control constitucional, el papel del juez no es el de evaluar si la ponderación realizada por el legislador a la hora de definir las reglas que regulan y, en consecuencia, limitan los derechos, son las mejores. Su función constitucional es simplemente la de controlar los virtuales excesos del poder constituido o, en otras palabras, las limitaciones arbitrarias, innece-

\footnotetext{
19 Corte Constitucional. Sentencia T-426 de 1992. M.P. Eduardo Cifuentes Muñoz. Reiterado en las sentencias T-047 de 1995. M.P. Vladimiro Naranjo Mesa, T-576 de 1998. M.P. Alejandro Martínez Caballero, C-116 de 1999. M.P. Martha Victoria Sáchica Méndez, C-942 de 2009. M.P. Jorge Ignacio Pretelt Chaljub.
} 
sarias, inútiles o desproporcionadas de los derechos fundamentales. Para ello, se ha elaborado un arsenal hermenéutico que vincula al funcionario judicial con criterios de decisión como sus propios precedentes, el juicio de proporcionalidad o de razonabilidad, la aplicación del principio de concordancia práctica o armonización concreta, que surgen de las fuentes del derecho y que deben ser expuestos de manera clara en los motivos que fundamentan una determinada decisión judicial"20.

En este orden de ideas, el alto tribunal ha explicado que en Colombia opera el llamado juicio integrado de proporcionalidad, que comprende dos grandes enfoques para el examen de la razonabilidad de las medidas que limitan derechos fundamentales u otros principios constitucionales: uno de origen europeo, que se desprende del juicio de proporcionalidad, y otro de origen estadounidense, que diferencia distintos niveles de intensidad dependiendo de la materia sometida a control (test de intensidad):

"El juicio integrado de proporcionalidad, que combina las ventajas del análisis de proporcionalidad de la tradición europea y de los tests de distinta intensidad estadounidenses, implica entonces que la Corte comienza por determinar, según la naturaleza del caso, el nivel o grado de intensidad con el cual se va a realizar el estudio de la igualdad, para luego adelantar los pasos subsiguientes con distintos niveles de severidad. Así, la fase de 'adecuación' tendrá un análisis flexible cuando se determine la aplicación del juicio dúctil, o más exigente cuando corresponda el escrutinio estricto. Igualmente sucederá con los pasos de "indispensabilidad" y 'proporcionalidad en estricto sentido" "21.

Así, se evidencia que lo que diferencia estas tres intensidades es "su estructura, sus elementos de análisis y sus consecuencias en materia probatoria y argumentativa" (CORTE ConsTitUCIONAL, Sentencia C-673 de 2001, M.P. Manuel José Cepeda Espinosa). Así, se busca "cuando el test es leve, por una parte, a determinar si el fin buscado y el medio empleado no están constitucionalmente prohibidos y, por otra, a establecer si el medio escogido es adecuado, esto es, es idóneo para alcanzar el fin propuesto" (CoRTe Constitucional, Sentencia C-673 de 2001, M.P. Manuel José Cepeda Espinosa), como punto de partida del análisis de la razonabilidad y mecanismo ordinario de estudio del tratamiento diferenciado.

Por otra parte, se da aplicación a un test estricto de razonabilidad cuando por ejemplo (i) está de por medio una clasificación sospechosa como las enumeradas en forma no taxativa a manera de prohibiciones de discriminación en el inciso $1^{\circ}$ del artículo 13 de la Constitución; (ii) cuando la medida recae principalmente en personas en condiciones de debilidad manifiesta, grupos marginados o discriminados, sectores sin acceso efectivo a la toma de decisiones o minorías; (iii) cuando la medida que hace la diferenciación entre personas o grupos prima facie afecta gravemente el goce de un derecho constitucional fundamental; (iv) cuando se examina una medida que crea un privilegio.(Corte Constitucional, Sentencia C-673 de 2001, M.P. Manuel José Cepeda Espinosa). Este test estricto comporta la característica de incorporar la aplicación de un juicio de proporcionalidad en sentido estricto como último paso del Test de razonabilidad; la Sentencia C-673 de 2001, M.P. Manuel José Cepeda Espinosa, define el precitado concepto como aquel que

\footnotetext{
20 Corte Constitucional. Sentencia C-475 de 1997. M.P. Eduardo Cifuentes Muñoz.

21 Corte Constitucional. Sentencia C-093 de 2001, M.P. Alejandro Martínez Caballero). Véase al respecto la sentencia de la Corte Constitucional Sentencia C-372 de 2011, M.P. Jorge Ignacio Pretelt Chaljub que reitera este contenido.
} 
exige "que los beneficios de adoptar la medida excedan claramente las restricciones impuestas sobre otros principios y valores constitucionales por la medida".

Con la anterior afirmación, no se quiere decir que la ponderación garantiza una articulación sistemática material de todos los principios jurídicos, que resuelva de antemano todas las posibles colisiones entre ellos. Considera la Corte Constitucional que a este respecto, por el contrario y citando a Robert Alexy que, "al igual que el silogismo, la ponderación es sólo una estructura, que está compuesta por tres elementos, mediante los cuales se puede fundamentar una relación de precedencia condicionada entre los principios en colisión, para así establecer cuál de ellos debe determinar la solución del caso concreto"22.

Para Jaime Araújo Rentería, exmagistrado y expresidente de la Corte Constitucional, la técnica apropiada para resolver los conflictos entre principios constitucionales es la ponderación: "La ponderación de principios consiste en instituir entre los dos principios en conflicto una jerarquía axiológica móvil”23. Para el ex magistrado, la operación de ponderación comporta una doble discrecionalidad: (i) La institución de una jerarquía de valores entre los principios implicados y (ii) el cambio relativo de valor de los principios al tenor de los diferentes casos concretos.

\subsection{IMPORTANCIA Y USOS JURISPRUDENCIALES}

En el caso colombiano, el uso de la metodología de la ponderación se ha extendido a la mayoría de ramas del derecho y goza de general aceptación en el panorama decisional de los jueces. Evidencia de la anterior afirmación es la abundancia de jurisprudencia que utiliza su estructura para la construcción del marco de sus decisiones, preponderantemente en sede de igualdad. Responsabilidad estatal, derecho penal, autonomía de las comunidades indígenas, derecho fiscal, tutela contra sentencias judiciales, relaciones vecinales, servicio social obligatorio en el ejercicio de las profesiones, entre otros, son temas en las que el criterio de ponderación ha estado fuertemente presente en materia de tutela y constitucionalidad.

El proceso de constitucionalización, sufrido por la mayoría de ramas del derecho a partir de la expedición de la Constitución Política de 1991, ha llevado a que los principios, valores y derechos constitucionales no sean conceptos ajenos o exóticos a la jurisdicción ordinaria y contencioso-administrativa a la hora de aplicar el derecho, en la medida en que no sólo se integran como parámetros de constitucionalidad, sino que se adoptan sus mecanismos de aplicación para la toma de decisiones ordinarias, con el fin de llegar a fallos justos y razonables.

Materias como por ejemplo la responsabilidad estatal, específicamente por la falla en el servicio, han tomado la ponderación como el factor central de la toma de sus decisiones. Para la imputación de dicha responsabilidad, por ejemplo, la sentencia 2000-1940 de junio 7 de 2012 de la sección tercera del Consejo de Estado, con ponencia de Jaime Orlando Santofimio Gamboa afirma que:

"Se busca la aplicación, en sede del contencioso administrativo, del principio de proporcionalidad, el cual no está vedado o prohibido de aplicación, ni se puede considerar solamente como una herramienta para resolver las tensiones constitucionales entre derechos, intereses y

\footnotetext{
22 AleXY, Robert, op. cit. (n. 1), pp. 90 y ss.

23 Araújo Rentería, Jaime. "Los métodos judiciales de ponderación y coexistencia de derechos fundamentales. Crítica”, en: Anuario de Derecho Constitucional Latinoamericano, 2006, Instituto de Investigaciones Jurídicas, Universidad Autónoma de México, México, 2006, p. 13.
} 
principios, sino que cabe afirmarlo, a partir del sub-principio de ponderación y del principio de la razonabilidad...”.

Considera el Consejo de Estado que el juicio de imputación de responsabilidad, "obedece sin lugar a dudas a un ejercicio de la ponderación que el juez está llamado a aplicar, de tal manera que se aplique como máxima que: "Cuanto mayor sea el grado de la no satisfacción o del detrimento de un principio, mayor debe ser la importancia de satisfacción del otro".

En materia de Seguridad Social, la Sala Laboral de la Corte Suprema de Justicia, en sentencia de 8 de abril de 2008, rad. № 28547, M.P. Gustavo José Gnecco Mendoza en la que se consideró en materia de pensión de sobrevivientes que:

"El resultado denegatorio de una pensión de sobrevivientes, perteneciente al mismo, por un faltante de 0.29 centésimas de una cifra, ciertamente que habilitaban al juzgador para ponderar adecuadamente la tensión resultante de la literalidad normativa con la equidad como criterio auxiliar, dentro del marco de la calidad de Estado Social de Derecho insuflado a Colombia por la Carta de 1991.Y esa ponderación se torna imperativa porque, a diferencia de lo expuesto por la censura sobre la presunta actitud del conglomerado social respecto de las previas reglas fijadas para dispensar las prestaciones propias del Sistema de Seguridad Social Integral, una solución denegatoria, en el caso de la pensión de sobrevivientes, con compañera permanente e hijo involucrados, bajo el adusto y lapidario argumento de la aplicación ad litteram de la preceptiva en cuestión, lo que genera es un sentimiento de reprobación social ante el despropósito al que se llega, ya que es ostensible la vastísima desproporción entre los perjuicios trascendentes generados para quienes son excluidos de los beneficios del sistema por el írrito guarismo, con los presuntos que recibe el sistema al dispensar la prestación bajo las especialísimas circunstancias del sub lite".

En este caso, la justicia ordinaria crea una norma basada en la ponderación para el otorgamiento de pensiones cuando es más nugatoria de los derechos fundamentales la ínfima cantidad numérica para acceder al requisito de la norma legal y la correspondiente falta de reconocimiento del derecho pensional. A la misma conclusión se llegó en el fallo de la Sala Laboral de la misma corporación de 30 de agosto de 2011, rad. 42029, M.P. Jorge Mauricio Burgos Ruiz, respecto al tema de la pensión de invalidez y la ponderación para su otorgamiento en criterios de equidad.

De otra parte, es pertinente anotar que la Sala Laboral de la Corte Suprema de Justicia ha utilizado el término de ponderación para referirse al modo en que el juez debe valorar las pruebas por medio de su sana crítica

\subsection{Críticas metodológicas}

Para los críticos, la ponderación constituye un mecanismo irracional principalmente por su indeterminación, la inconmensurabilidad en su aplicación y la imposibilidad de predecir sus resultados.

Una de las objeciones más importantes señala que se trata de una simple fórmula retórica que constituye una técnica de poder con una estructura jurídica imprecisa, puesto que no existen criterios jurídicos suficientes para garantizar su objetividad, de manera tal que sirvan de mecanismo de control de las providencias que ponderan principios (LEISNER-STAMMLER). Se dice que se trata de una estructura meramente formal en la que las apreciaciones subjetivas del juez son la balanza con la que se pondera. 
El problema de la inconmensurabilidad sale a flote, puesto que no existe una organización jerárquica de principios, ni siquiera una medida común entre ellos para determinar su peso en cada caso; no existe una unidad de medida (Betterman-García Amado-Habermas). Por último, se tiene que es imposible predecir los resultados de la ponderación puesto que la misma no se ciñe a criterios generales, conformando así una jurisprudencia ad hoc (ALEINKOFFBethge).

Ya de manera local, para el ex presidente de la Corte Constitucional colombiana, JAIME Araújo Rentería, la crítica fundamentalmente se centra en que las intensidades del juicio de ponderación en Colombia se determinan en el test de razonabilidad de intensidad variable llamado "test de escrutinios" de acuerdo a unos criterios dados por el mismo tribunal, tomando los tests de intensidad de la jurisprudencia norteamericana ${ }^{24}$. Para el ex magistrado, estas clasificaciones son "subjetivas" y "caprichosas", y "lleva a que la Corte Constitucional "se case con la tesis de que a ciertas materias se les aplique de antemano un test de intensidad determinada" que la Constitución no autoriza" ${ }^{25}$. Además de lo anterior, considera que debe ampliarse el espectro de aplicación de la ponderación a todos los derechos fundamentales, en el sentido en que en Colombia el mismo ha sido de cierta manera reducido a un simple test de igualdad. Finalmente, concluye que:

"La interpretación por medio de valores o principios representa dos grandes inconvenientes: 1) que los valores que no están previamente definidos son siempre subjetivos y 2) que, como no existe una jerarquía de principios sino una escala móvil, (...) no existe nunca certeza jurídica ni regla general, lo que crea inseguridad, porque nunca se sabe cómo fallará el juez y, lo que es más importante, el derecho se convierte en un catálogo de casos"26.

Ahora bien, otra de las críticas importantes frente a la implantación de la ponderación, como método de aplicación constitucional, es la falta de destreza teórica de los jueces, que muchas veces llega no sólo a la intromisión por parte de los tribunales constitucionales en la competencia legislativa abusando de cierta manera de la interpretación constitucional, sino que muchas veces crea conflicto de principios en donde no existe, atentando de esta manera contra el principio democrático a través de regulaciones particularistas de falsas lagunas axiológicas que sobre interpretan los contenidos del texto constitucional.

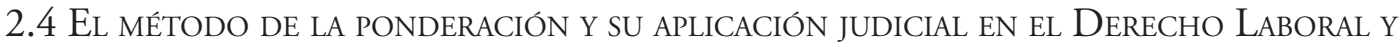
la Seguridad Social

La jurisprudencia de la Corte Constitucional, ha sido enfática en definir que su labor fundamental es guardar la supremacía y la integridad de la Constitución, de manera tal que la misma,

\footnotetext{
24 Así por ejemplo la Corte Constitucional en Sentencia C-673 de 2001, M.P. Manuel José Cepeda Espinosa afirmó que: "En diversas hipótesis la Corte ha optado por aplicar un test leve de razonabilidad, como por ejemplo en ciertos casos que versan exclusivamente sobre materias 1) económicas, 2) tributarias, 3) de política internacional, sin que ello signifique que el contenido de una norma conduzca inevitablemente a un test leve. .. 4) cuando está de por medio una competencia específica definida por la Constitución en cabeza de un órgano constitucional, 5) cuando se trata del análisis de una normatividad preconstitucional derogada que aún surte efectos en el presente, y 6) cuando del contexto normativo del artículo demandado no se aprecie prima facie una amenaza para el derecho en cuestión".

25 Araújo Rentería, Jaime, op. cit. (n. 23), pp. 24 y ss.

26 Ibid.
} 
debe ser la encargada de interpretar con autoridad y definir los alcances de los preceptos constitucionales. En la sentencia C-037 de 1996, sentencia de revisión de constitucionalidad de la Ley Estatutaria de Administración de Justicia, se establece este concepto, legitimado por la Constitución misma en su artículo 241. Se tiene entonces, que el control constitucional es "el que se ejerce por un órgano competente a través de un pronunciamiento definitivo respecto de la concordancia de ciertas normas jurídicas con la integridad y la primacía de la Carta Política"27, y a su vez explica que, dentro del esquema de la rama judicial, el control de constitucionalidad es ejercido por parte de la Corte Constitucional, en forma directa y principal, e hizo que en Colombia se haya visto reforzada dicha figura. Sin embargo, este aporte del Tribunal no quiere decir que en nuestro país opere la figura del control concentrado de Constitucionalidad per se. Si bien la Corte Constitucional lo ejerce de forma principal, no es el único órgano que cumple con esta función; lo cumplen todos los jueces y tribunales, lo que, vale aclarar, tampoco lo convierte en un sistema de control difuso.

El sistema de control de constitucionalidad colombiano combina los dos sistemas de control constitucional, siendo entonces un "control difuso funcional" tal como lo expresa la Corte Constitucional. Se trata de un proceso de constitucionalidad mixto que combina elementos del modelo difuso y del concentrado. La existencia de la Corte Constitucional implica el fortalecimiento de la dimensión concentrada del sistema. Sin embargo, se desconcentra la función de control constitucional en el Consejo de Estado, mediante las acciones de nulidad por inconstitucionalidad y en todos los jueces o autoridad administrativa, a través de la excepción de inconstitucionalidad, al abstenerse de aplicar una norma, en un caso concreto y con efectos inter-partes, en aquellos eventos en que ésta contradiga manifiestamente la Constitución. Finalmente, cada uno de los jueces de la República -al resolver las acciones de tutela- conforma esta estructura de control en la que se preserva la supremacía constitucional, mediante la garantía inmediata de los derechos fundamentales.

Veamos entonces cómo ha tomado parte de la jurisdicción constitucional colombiana la ponderación como método de aplicación del texto constitucional para la resolución de conflictos, entre principios derivados de las relaciones laborales y de la seguridad social en todos sus ámbitos.

\subsubsection{El uso de la tutela en materia laboral y de seguridad social en Colombia}

El instrumento jurídico de la Acción de Tutela se ha consolidado como uno de los mecanismos por excelencia para la reivindicación de los derechos fundamentales conculcados en asuntos laborales y de seguridad social. Lo anterior, en virtud de la proliferación de la utilización de esta herramienta procesal de protección de derechos fundamentales desde su consagración en la Constitución Política de 1991. Antes de esto, en el ordenamiento jurídico colombiano no existía una figura que permitiera la protección de los derechos fundamentales en caso de ser conculcados. Desde su implementación, la jurisdicción constitucional ha atendido más de cuatro millones de acciones de tutela, de las cuales, gran parte reclaman la protección de derechos laborales y de seguridad social, siendo hoy casi el $70 \%$ los casos referentes a estas materias, los que ocupan a la jurisdicción constitucional en sede de tutela.

Su aplicación y desarrollo ha conllevado la necesidad de conceptualizar y delimitar el alcance de los derechos fundamentales, que han permitido a todas las personas el acceso a la administración de justicia, mediante un procedimiento sencillo, ágil y eficaz. La tutela, que es la

\footnotetext{
27 Ver las sentencias de la Corte Constitucional C-037 de 1996, M.P. Vladimiro Naranjo Mesa, C-739 de 2001 M.P. Álvaro Tafur Galvis y C-713 de 2008, M.P. Clara Inés Vargas Hernández.
} 
acción más importante y de mayor influencia en el sistema jurídico colombiano, ha propiciado modificaciones en Colombia en lo que se conoce como proceso de constitucionalización del derecho. Asuntos tales como las relaciones laborales y las prestaciones de la seguridad social, han experimentado un cambio notable en su desarrollo y eficacia desde la implementación de este mecanismo procesal. Cuando quiera que los derechos fundamentales devenidos de las relaciones laborales y de seguridad social, resulten vulnerados o amenazados por las autoridades públicas o particulares en ciertos casos, siempre que no existan otros mecanismos de defensa judicial, salvo que se utilice como mecanismo transitorio para evitar un perjuicio irremediable, procede la acción de tutela para su protección.

Los temas laborales no han escapado a la aplicación del juicio de ponderación como mecanismo de resolución de colisiones de principios y derechos fundamentales. Puede decirse que la ponderación ha sido utilizada no sólo para determinar el valor relativo de ciertos principios y derechos constitucionales, frente a otros de la misma categoría, sino que ha servido incluso para otorgarle carácter absoluto a ciertas disposiciones en virtud de un juicio constante de ponderación en los casos particulares que ha sentado un precedente constitucional importante frente a la materia.

\subsubsection{Estudio de casos relevantes en las distintas ramas del Derecho del Trabajo y la Seguridad Social}

\subsubsection{El valor absoluto otorgado a través de la ponderación}

En una primera aproximación jurisprudencial, en Colombia se observa que la ponderación ha servido no solo para ajustar el valor de los principios constitucionales en juego de acuerdo con el caso concreto, sino que también ha sido utilizada para otorgar valor absoluto a ciertos principios y derechos fundamentales.

Ejemplo del valor absoluto otorgado a través de la ponderación, es el entendimiento del derecho al ajuste de la primera mesada pensional como absoluto. La sentencia de tutela T-697 de 2010, M.P. Juan Carlos Henao Pérez concluye que:

"El concepto de que el derecho a la indexación de la primera mesada pensional es un derecho universal, fundamental, irrestricto para todas las personas que ostenten la calidad de pensionados, es producto de una ponderación minuciosa llevada a cabo por la Corte Constitucional, incluso con anterioridad a la Sentencia C-862 de 2006, y por ello tiene el valor de norma adscrita a la Constitución Política"28.

Lo anterior lo considera el alto tribunal entendiendo a estas normas como el resultado de una ponderación ius fundamentalmente correcta efectuada por el órgano que ejerce el control constitucional en concordancia con la teoría alemana de Robert Alexy. Para la Corte Constitucional, la indexación del ingreso base de liquidación, procede a través de conceptos como la equidad, el principio in dubio pro operario, la indexación de las sentencias por inflación, el principio de progresividad, entre otros; más aún, valores como la solidaridad y la equidad, que son características objetivas y a priori del derecho, y:

\footnotetext{
28 Reiterado en las sentencias de la Corte Constitucional T-901 de 2010, M.P. Juan Carlos Henao Pérez, T-835 de 2011, M.P. María Victoria Calle Correa.
} 
"Que deben ser tenidos en cuenta por el juez al momento de valorar las conductas. La universalidad del concepto de indexación entre todos los pensionados podría sostenerse, únicamente, en que la justicia es finalidad primordial del derecho, y en las bases éticas en que se apoya la sociedad, conforme a las cuales la protección a las personas de la tercera edad debe ser prioritaria, plena, efectiva y proporcional"29.

\subsubsection{La ponderación en el derecho procesal del trabajo y la seguridad social}

Habiendo cuenta del sistema mixto implantado en Colombia y a través del consecuente juicio integrado de proporcionalidad, la sentencia C-372 de 2011, M.P. Jorge Ignacio Pretelt Chaljub determina su contenido de la siguiente manera:

"Este juicio integrado comprende entonces las siguientes etapas: (i) evaluación del fin de la medida, el cual debe ser no solamente legítimo sino importante a la luz de la Carta; (ii) análisis de si la medida es adecuada, es decir, de su aptitud para alcanzar un fin constitucionalmente válido; (iii) estudio de la necesidad de la medida, es decir, análisis de si existen o no otras medidas menos gravosas para los derechos sacrificados que sean idóneas para lograr el mismo fin; y (iv) examen de la proporcionalidad en estricto sentido de la medida, lo que exige una ponderación costo -beneficio de las ventajas que trae las medida frente al eventual sacrificio de otros valores y principios constitucionales. Sin embargo, previo a este estudio, el operador jurídico debe establecer cuál es el grado de intensidad con el que adelantará su análisis, es decir, si aplicará un juicio estricto, moderado o débil, dependiendo de la naturaleza misma de la medida ${ }^{30 ”}$.

Esta providencia, estudia la constitucionalidad de la Ley 1395 de 2010, por la cual se adoptan medidas en materia de descongestión judicial cuyo artículo 48 establece:

"Modifíquese ${ }^{31}$ el artículo 86 del Código Procesal del Trabajo y de la Seguridad Social, el cual quedará así: Artículo 86. Sentencias susceptibles del recurso. A partir de la vigencia de la presente ley y sin perjuicio de los recursos ya interpuestos en ese momento, sólo serán susceptibles del recurso de casación los procesos cuya cuantía exceda de doscientos veinte (220) veces el salario mínimo legal mensual vigente".

De acuerdo con el esquema planteado anteriormente, la Corte Constitucional considera que la intensidad del juicio con que debe ser estudiado el artículo 48 de la Ley 1395 de 2010 es intermedio, en atención a lo siguiente:

“(i) el Constituyente reconoció al legislador un amplio margen de libertad de configuración en materia de establecimiento de procedimientos (C.P., art 150, núm. $2^{\circ}$ ); (ii) esta amplia competencia también ha sido reconocida por la jurisprudencia constitucional, específicamente en el establecimiento de cuantías; sin embargo, (iii) pese a que las dos consideraciones anteriores podrían llevar a la aplicación de un test leve, considera esta Sala que en razón a que se alega

\footnotetext{
29 Concepto reiterado en las sentencias T-697 y T-901 de 2010, M.P. Juan Carlos Henao Pérez.

30 Véase también las sentencias C-598 de 2011, M.P. Jorge Ignacio Pretelt Chaljub y C-093 de 2001, M.P. Alejandro Martínez Caballero.

31 La cuantía se fijaba en 120 SMLMV.
} 
una posible afectación de los derechos a la igualdad, a acceder a la administración de justicia, al trabajo, a la seguridad social y de las demás garantías consagradas en el artículo 53 superior, se justifica el escrutinio intermedio".

El alto tribunal concluye que, si bien la norma fue adoptada con el objeto de descongestionar la justicia laboral, en virtud del test intermedio, la medida debe ser efectivamente conducente. Es decir, la medida debe alcanzar el fin propuesto por la norma con un importante grado de probabilidad. Ahora bien, si se reduce el número de recursos de casación interpuestos, la medida no soluciona los problemas de mora judicial en las instancias y en los despachos de los jueces de inferior jerarquía, cuyo trabajo tiene una incidencia directa en la cantidad de procesos que van a ser conocidos por la Sala Laboral, ni reducirá el número de controversias conocidas en general por la jurisdicción laboral. "La medida solamente conduce a reducir la carga de trabajo de la Sala de Casación Laboral, lo cual no puede identificarse con el concepto de descongestión judicial. Por lo anterior, la Sala concluye que el medio no es idóneo para el alcanzar el fin propuesto ni mucho menos conducente". (Corte Constitucional, Sentencia C-372 de 2011, M.P. Jorge Ignacio Pretelt Chaljub).

En la misma providencia, considera la Corte Constitucional "que la medida no es proporcionada en estricto sentido y, por el contrario, sacrifica otros valores y principios constitucionales de trascendental importancia, como el derecho a la igualdad, el derecho a acceder a la administración de justicia, el derecho al trabajo y otras garantías de los trabajadores". Lo anterior, en el sentido en que si se reducen los asuntos conocidos por la Sala Laboral de la Corte Suprema de Justicia, existirán numerosos conflictos laborales que aunque de extremada naturaleza compleja pero baja cuantía, quedarían en los Tribunales, siendo ellos quienes en definitiva determinarían los alcances de la legislación laboral. Obsérvese como la ponderación ha impregnado el campo del derecho procesal del trabajo y la seguridad social.

Finalmente, la Carta considera que la medida atenta contra el principio de progresividad y de no regresividad, que es aplicable a todas las facetas prestacionales de los derechos, razón con la cual concluye su análisis de constitucionalidad y declara el artículo 48 de la Ley 1395 de 2010 inexequible.

\subsubsection{La ponderación en el derecho individual y las prestaciones sociales}

La sentencia C-825, de octubre 4 de 2006, M.P. Jaime Araújo Rentería realiza el estudio de constitucionalidad del artículo 306 (parcial) del Código Sustantivo del Trabajo, disposición en la cual se excluye la prima de servicios de las prestaciones debidas a los trabajadores accidentales o transitorios.

Esta providencia realiza un ejercicio argumentativo tendiente a elaborar un juicio de igualdad entre los distintos tipos de trabajadores, esencialmente, entre los trabajadores permanentes y los accidentales y transitorios. Al respecto considera la citada providencia que:

"Los conflictos en que entra en juego el derecho a la igualdad muestran que las normas que lo consagran pueden ser tratadas como principios, esto es, son normas cuya aplicación en un caso concreto depende de la ponderación que se haga frente a los principios que con él colisionan... Corresponde al juez hacer la ponderación entre el principio a la igualdad y el principio que entra en conflicto con él, y decidir sobre la prevalencia de uno de ellos en el caso concreto, a la 
luz del ordenamiento constitucional". (CORTe Constitucional, sentencia C-825 de octubre 4 de 2006, M.P. Jaime Araújo Rentería).

Explica el tribunal constitucional que, cuando el legislador decidió excluir a los trabajadores accidentales o transitorios, lo hizo con el fin de proteger un modelo económico. Sin embargo:

"Analizada dicha exclusión desde la perspectiva del principio de proporcionalidad, vale decir, estableciendo un juicio de ponderación entre medios y fines, la autorización de un privilegio a expensas de unos derechos como son las prestaciones sociales, de conformidad con nuestro desarrollo constitucional hoy, representa un medio no permitido. Si dicho principio exige además que el medio sea idóneo y necesario, es decir, que sea adecuado y que solo por su intermedio se logre el fin buscado por no existir otra alternativa menos gravosa, la negación de esta prestación contradice nuestro orden constitucional por ser desproporcionada respecto del estímulo que quiso otorgarse a algunos empleadores".

Las anteriores razones llevan a la Corte Constitucional Colombiana a declarar inexequible la expresión "excepto a los ocasionales o transitorios" del artículo 306 del Código Sustantivo del Trabajo.

\subsubsection{La ponderación como medida de configuración del contrato realidad}

La sentencia T-629 de agosto 13 de 2010, M.P. Juan Carlos Henao Pérez, resuelve la "Acción de tutela instaurada por Lais contra el Bar Discoteca Pandemo". La señora Lais instauró acción de tutela contra el Bar Pandemo, como mecanismo transitorio para evitar un perjuicio irremediable, por la presunta vulneración de sus derechos fundamentales al trabajo, la seguridad social, la igualdad, el debido proceso, la salud, la dignidad, la protección de la mujer en estado de embarazo, el derecho del que está por nacer, el fuero materno y el mínimo vital.

Como hechos relevantes al caso, es pertinente ilustrar que la actora ingresó a laborar como prostituta en el Bar Pandemo, "mediante contrato de trabajo verbal e indefinido", en horario de tres de la tarde a tres de la mañana, con descanso un domingo cada 15 días y salario de conformidad con los servicios prestados por venta de licor. El día $1^{\circ}$ de diciembre de 2008, la actora le informó a su empleador, a través del administrador del bar, de su estado de embarazo. Este le indicó que siguiera laborando normalmente con el horario de costumbre y así laboró hasta el 16 de enero de 2009, puesto que el día 17 de enero del 2009, la actora informó al empleador, que su médico tratante le había indicado que su embarazo era de alto riesgo por esperar mellizos. El empleador le dio entonces la orden de administrar el bar, hasta el día 23 de marzo de 2009, pues el 24 de marzo, "yo tenía cita médica a las dos y media de la tarde, la cual le había informado a mi empleador, llegué a laborar a las tres y veinte minutos de la tarde y me devolvió me [sic] empleador". El día siguiente, sigue la actora, "me presenté a laborar y nuevamente me negó el acceso a laborar y el día 26 me comunicó mi empleador que, no había más empleo dado que [por el] estado de embarazo [sic] de alto riesgo (...) ya había contratado a otra persona para desempeñar mi labor que estaba desempeñando".

Empieza la Corte Constitucional haciendo un análisis de legalidad de la prostitución y recordando que una de las expresiones de la cláusula de igualdad consagrada en el artículo 13 superior es la protección de los grupos tradicionalmente discriminados o marginados: "El Estado 
promoverá las condiciones para que la igualdad sea real y efectiva y adoptará medidas en favor de grupos discriminados o marginados", "condición que en el Estado social de derecho determina a la vez un mandato de abstención o interdicción de tratos discriminatorios y un mandato de intervención, a través del reconocimiento de exigencias al Estado que le imponen realizar acciones tendentes a superar las condiciones de desigualdad material que enfrentan dichos grupos"32. Este es el caso de las mujeres, y más aún de aquellas que ejercen la prostitución. Constitucional y legalmente se han ido desarrollando una serie de acciones afirmativas con el fin de obtener la igualdad de la mujer en la sociedad, dentro de las que sobresalen las que operan en el ámbito laboral, como posiciones jurídicas diferenciales de estabilidad laboral reforzada, predicable para la mujer trabajadora en embarazo o en periodo de lactancia o para cuando funge en su hogar como madre cabeza de familia.

De manera general, el problema jurídico planteado consiste en saber si es aceptable que una persona acepte obligarse a la prestación de servicios sexuales que desarrolla por cuenta ajena, sometida a condiciones de subordinación y dependencia, a cambio de un salario. Lo anterior, sumado a que la persona que ejerce la prostitución es una mujer embarazada, madre y cabeza de familia, razón por la cual se pregunta si también debería ampararse la garantía de estabilidad reforzada laboral que se predica en general de este tipo de mujeres en sus relaciones laborales.

Recalca además el Alto Tribunal, la existencia del test integrado de proporcionalidad "que aprovecha del mayor poder analítico del juicio de proporcionalidad, con el carácter diferencial del test de igualdad, con el cual se propone mantener una relación inversamente proporcional entre la facultad de configuración del legislador y la facultad de revisión del juez constitucional, con el fin de proteger al máximo el principio democrático". (CoRte Constitucional, Sentencia T-629 de agosto 13 de 2010, M.P. Juan Carlos Henao Pérez).

Ahora bien, determina la Corte Constitucional que a pesar que desde la perspectiva jurídica de la igualdad, no existe en la Constitución -de manera explícita- ninguna disposición que autorice una discriminación negativa para las personas que ejercen la prostitución:

"El desconocimiento del derecho laboral para los y las trabajadores sexuales, porque con esta medida se restringen derechos fundamentales (al trato digno, al libre desarrollo de la personalidad y ante todo a ganarse la vida, al trabajo, a recibir una remuneración justa y equitativa) y se afecta de manera desfavorable a una minoría o grupo social tradicionalmente discriminado que se encuentra por tanto en condiciones de debilidad manifiesta".

En este orden de ideas, es forzoso concluir que:

"A falta de regulación concreta, y de la mano de la construcción normativa que ordena la prostitución en Colombia, en la medida en que se hayan desempeñado las mencionadas labores y en ese tanto el ejercicio de la prostitución se desenvuelva bajo la modalidad del "contrato realidad", esta situación merecerá, como ocurriría con cualquier otro sujeto en condiciones similares, la más decidida protección por parte del derecho para que sean cubiertas todas las obligaciones no pagadas por el empleador durante el tiempo en que hubiese tenido lugar la relación de trabajo. Empero, por la especificidad de la prestación, porque en muchos aspectos el trabajo sexual roza con la dignidad, así como se admite la existencia de una subordinación precaria por parte del empleador, también se reconoce precario el derecho del trabajador a la estabilidad laboral y a ser

32 Corte Constitucional, Sentencia T-629 de agosto 13 de 2010, M.P. Juan Carlos Henao Pérez. 
restituido a su trabajo en caso de despido injusto". (CoRTe Constitucional, Sentencia T-629 de agosto 13 de 2010, M.P. Juan Carlos Henao Pérez).

\subsubsection{La ponderación en el derecho colectivo del trabajo}

Hemos visto como varias veces, de mano del principio de igualdad y a través del juicio integrado de proporcionalidad, se han presentado evidencias en el campo procesal del trabajo y la seguridad social, laboral individual y de seguridad social. Tal ha sido el influjo y la implantación de esta mixtura de teorías europeas y norteamericanas que, para finalizar con las ramas del derecho del trabajo y la seguridad social, encontramos evidencia de su utilización para la resolución de conflictos de derecho laboral colectivo.

La sentencia T-434 de 2011, M.P. Mauricio González Cuervo, estudia el caso de SINTRAINDULECHE, sindicato de una empresa colombiana de productos y derivados lácteos. El conflicto se origina con el retiro por parte de la empresa, de los medios publicitarios a través de los cuales el sindicato manifestó su defensa al pliego de peticiones, adicionalmente, sanciona en su Reglamento Interno de Trabajo la distribución de materia publicitario, imponiendo las sanciones disciplinarias previstas en dicho reglamento a quienes participaron de esta actividad de defensa del pliego. Según la Corte Constitucional en esta oportunidad, "el asunto que se discute entonces no es el de la negociación colectiva como tal, sino de la eventual violación de los derechos fundamentales del sindicato en el marco de la misma”.

Habida cuenta del conflicto surgido entre el ejercicio de la libertad de empresa, que comprende el derecho de imponer el reglamento de trabajo y el poder disciplinario del empleador, y de otra parte, la efectividad de los derechos a la asociación sindical, la negociación colectiva y la libertad de expresión. Considera la Corte Constitucional que en el presente caso se debe hacer un ejercicio de armonización para resolver la colisión entre derechos fundamentales, realizando, en primer lugar:

"Un juicio de idoneidad de las medidas orientado a establecer si la restricción a los derechos fundamentales que se consideran vulnerados, permite realizar un fin legítimo o un interés de naturaleza constitucional. En segundo lugar, será necesario realizar un juicio de necesidad que permita determinar si las restricciones realizadas por la empresa son indispensables para lograr el fin legítimo, o si existen medidas menos lesivas de los derechos de los trabajadores y del Sindicato. Finalmente, y siempre que sean superados los juicios de idoneidad y de necesidad, se realizará el juicio de proporcionalidad en sentido estricto basado en la ley de la ponderación que permite asignar peso a los derechos en colisión y establecer una comparación entre los mismos". (Corte Constitucional. Sentencia T-434 de 2011, M.P. Mauricio González Cuervo).

Para la realización de estos fines, el tribunal procede a resaltar que, en el marco de los procesos de negociación colectiva, el sindicato cuenta con el derecho a defender sus intereses como asociación de trabajadores y a comunicarlos no sólo a sus miembros, sino a todos los trabajadores de la empresa. Concluye la Corte Constitucional en la misma providencia que "la empresa puede regular, mas no anular el derecho de libre expresión sindical: puede, por ejemplo, establecer reglas de ubicación de afiches y similares en carteleras prefijadas por ella misma o autorizadas al sindicato, mas no ignorar su derecho de información sobre el curso y contenido de la negociación”. En efecto, la Corte Constitucional empieza a tener en cuenta la titularidad de derechos fundamentales radicados en cabeza de las organizaciones sindicales y considera, que, en el ejercicio de dichos 
derechos, como lo son la libertad sindical y la negociación colectiva, el sindicato debe estar en la capacidad de "expresar y defender sus intereses, difundiendo sus opiniones sobre el proceso, para que también los trabajadores conozcan la posición del sindicato y participen informadamente".

En su análisis argumentativo, el cuerpo colegiado constitucional ha indicado en su jurisprudencia que "ante la posibilidad de la utilización de mecanismos, para la defensa de intereses legítimos, no conciliables con otros principios, derechos y valores constitucionales, debe brindarse protección a los derechos fundamentales frente a los posibles abusos o excesos cometidos en las relaciones privadas laborales". Termina la Corte Constitucional por concluir al respecto, que:

\begin{abstract}
"En un contexto de negociación colectiva, habiendo estrategias de confrontación de parte y parte, el hecho de conferirle al empleador la posibilidad de restringir la libertad de expresión, herramienta fundamental del sindicato, es darle una ventaja inconstitucional y desproporcionada, que además vulnera los derechos de asociación sindical y negociación colectiva”. (Corte Constitucional. Sentencia T-434 de 2011, M.P. Mauricio González Cuervo).
\end{abstract}

\title{
3. CONCLUSIONES
}

La ponderación para la aplicación de principios constitucionales en conflicto, si bien se rige por cierta estructura y reglas lógicas que permiten una aplicación racional, siempre tiene espacio para la subjetividad del juez, toda vez que el recorrido argumentativo, tanto el grado de afectación de los principios, como su peso abstracto y la proporcionalidad en sentido estricto, a través de la argumentación del caso concreto, hacen parte de lo que es en sí la propia subjetividad del juzgador. Subjetividad sin embargo, no implica irracionalidad.

Es relevante advertir, de manera general, cuando acaecen conflictos de principios, que en numerosas ocasiones se deben a conflictos de reglas que se encuentran impregnadas de principios y por tanto, al ser excluyentes, el juez sacrifica una en beneficio de la otra, teniendo siempre en cuenta que, a veces las reglas también son excluyentes, en la medida en que desarrollan principios que se contradicen en un caso concreto. Corolario de lo anterior, es que la subsunción no es el único mecanismo de aplicación de reglas, cuando las mismas están contenidas de principios en conflicto.

Es significante destacar que la operación argumentativa efectuada a través de la estructura de la ponderación, comprende una doble discrecionalidad, en tanto que instituye un valor jerárquico a los principios en conflicto y cambia su valor relativo, de acuerdo al caso concreto.

América Latina, está atravesada por un amplio proceso de democratización que llevó a cambios trascendentales de índole constitucional. En el último siglo, sigue la tendencia a contener amplios catálogos de derechos fundamentales, principios y valores en sus Constituciones. Pese a que la región se encuentra fuertemente influenciada por el constitucionalismo europeo, el proceso de implantación de las ideas liberales y sus rasgos característicos, han llevado a numerosos autores a referirse a un "nuevo constitucionalismo latinoamericano" en razón a las particularidades de su establecimiento. Esto ha sucedido con las tesis alemanas de la ponderación las que, en la actualidad, no se consideran para nada lejanas a los sistemas constitucionales latinoamericanos. "De hecho, el principio de proporcionalidad constituye hoy en día quizá el más conocido y el más recurrente "límite de los límites" a los derechos fundamentales y en esa medida supone una barrera frente a intromisiones indebidas en el ámbito de los propios derechos". Como consecuencia de la implantación de este modelo constitucional en la región, los jueces constitucionales y los demás 
operadores jurídicos, han tenido que cambiar su perspectiva funcional, encaminándola hacia parámetros interpretativos nuevos que los llevan a operaciones de razonamiento más complejo, en las que las técnicas interpretativas propias de los principios constitucionales, hacen cada vez más frecuente el uso jurisprudencial de conceptos de aplicación constitucional como la ponderación, la proporcionalidad, la razonabilidad, la maximización de los efectos normativos de los derechos fundamentales, el efecto de irradiación y la proyección horizontal de los derechos fundamentales (drittwirkung).

Varios tribunales han hecho uso de este mecanismo adoptándolo a través de diversas denominaciones y caracterizaciones: bien sea entendiendo a sus subprincipios como un todo (idoneidad, necesidad y proporcionalidad stricto sensu) o como elementos separados y ajenos entre sí, o fusionándolo con otros tests de intensidades. En fin, a pesar de las diferencias dadas en su aplicación en los diferentes sistemas, se habla de elementos de una misma estructura cuando nos referimos a la proporcionalidad, la razonabilidad, la idoneidad y la necesidad.

En el caso colombiano, el proceso de constitucionalización sufrido por la mayoría de ramas del derecho -a partir de la expedición de la Constitución Política de 1991- ha llevado a que los principios, valores y derechos constitucionales no sean conceptos ajenos o exóticos a la jurisdicción ordinaria y contencioso-administrativa a la hora de aplicar el derecho, en la medida en que no sólo se integran como parámetros de constitucionalidad, sino que se adoptan sus mecanismos de aplicación para la toma de decisiones ordinarias, con el fin de llegar a fallos justos y razonables.

La tutela es la acción más importante y de mayor influencia en el sistema jurídico colombiano. Ella ha propiciado modificaciones en Colombia en lo que se conoce como proceso de constitucionalización del derecho. Asuntos tales como las relaciones laborales y las prestaciones de la seguridad social, han experimentado un cambio notable en su desarrollo y eficacia desde la implementación de este mecanismo procesal. Cuando quiera que los derechos fundamentales devenidos de las relaciones laborales y de seguridad social, resulten vulnerados o amenazados por las autoridades públicas o particulares en ciertos casos, siempre que no existan otros mecanismos de defensa judicial, salvo que se utilice como mecanismo transitorio para evitar un perjuicio irremediable, procede la acción de tutela para su protección.

Las razones por las cuales se presenta un alto y constante uso de la acción constitucional, van mucho más allá de los derechos fundamentales que comprenden la materia laboral y la seguridad social, procurando así evitar los complejos procesos ante la jurisdicción ordinaria laboral o la jurisdicción contencioso-administrativa, según sea el caso. Adicionalmente, se cuestiona la eficacia de la legislación y los procedimientos establecidos ante las distintas jurisdicciones, invitando a una reflexión y análisis acerca de los elementos que merecería un nuevo enfoque y replanteamiento.

Se considera que una de las críticas importantes, frente a la implantación de la ponderación como método de aplicación constitucional, es la falta de destreza teórica de los jueces, que muchas veces llega no sólo a la intromisión por parte de los tribunales constitucionales en la competencia legislativa abusando de cierta manera de la interpretación constitucional, sino que muchas veces crea conflicto de principios en donde no existe, atentando de esta manera contra el principio democrático a través de regulaciones particularistas de falsas lagunas axiológicas, que sobre-interpretan los contenidos del texto constitucional.

Sumado a la falta de destreza teórica se encuentra la falta de herramientas de capacitación y formación judiciales para el enfrentamiento a cuestiones constitucionales. Esta pedagogía judicial se considera indispensable dentro de un sistema jurídico, en el cual corresponde a todos los jueces y tribunales conocer de las acciones de tutela para la protección de los derechos fundamentales. 
Varias veces, de mano del principio de igualdad y a través del juicio integrado de proporcionalidad, se han presentado evidencias en los campos del derecho procesal del trabajo y la seguridad social, laboral individual y de seguridad social. Tal ha sido el influjo y la implantación de esta mixtura de teorías europeas y norteamericanas que, para finalizar con las ramas del derecho del trabajo y la seguridad social, encontramos evidencia de su utilización para la resolución de conflictos de derecho laboral colectivo. 